\title{
Scheer Digital World Congress 2016 Digitale Transformation: Best Practice in und für Unternehmen
}

Am 10. November 2016 treffen in Frankfurt Fachexperten beim Scheer Digital World Congress zusammen. Innovative Unternehmen geben ein hohes Tempo bei der strategischen und technischen Umsetzung der Digitalen Transformation vor. Die Gäste erwartet zum Beispiel ein Bericht über den strategischen Ansatz des Versicherers Cosmos zur effiziente Steuerung und Verbesserung seiner Services und Abläufe. Bei der Entwicklung smarter Oral-B-Produkte geht es um neue Businessmodelle ebenso wie beim Oberflächen- und Dekorhersteller FunderMax. Einen klaren Technologiefokus haben unter anderem die Vorträge des Unternehmens Harting als Produzent von Verbindungstechnologie zur Vernetzung von Maschinen und Anlagen und auch der von Q-Loud, einem Unternehmen, das sich auf Leistungen für das Internet of Things (IoT) spezialisiert hat.

In seiner Keynote wird Prof. Dr. August-Wilhelm Scheer unter anderem über die Notwendigkeit einer europäischen Aufholstrategie im Bereich der Digitalen Transformation sprechen. Durch Entwicklungen wie Industrie 4.0 wird deutlich, dass sich auch klassische Branchen, in denen Deutschland führend auf dem Weltmarkt ist, durch die IT verändern werden. Verfügt man jedoch in Deutschland und Europa nicht über die entsprechende IT-Kompetenz in Hard- und Software, kann man diese Branchen nur durch Kooperationen mit den USA und Asien modernisieren - das generiert Abhängigkeiten. Die Chance, sich an die Spitze der Entwicklung zu setzen, beziehungsweise dort zu bleiben, wird verpasst. Um die Führungsrolle in den erfolgreichen Branchen behalten und ausbauen zu können, wird eine entsprechende Digitalisierungskompetenz benötigt.

Im Ausstellungsforum werden die Experten der Scheer-Unternehmen aus ihren aktuellen Projekterfahrungen berichten und stehen, neben verschiedenen Partnerunternehmen, für Gespräche zur Verfügung. Im Digital Lounge Café wird Digitalisierung greifbar. Teilnehmer können hier Dank Scheer BPaaS ohne Vorkenntnisse ihre eigenen Digitalisierungsideen in Form einer Business-Anwendung in wenigen Minuten umsetzen. Ein spannendes Augmented-Reality-Szenario rundet das Rahmenprogramm ab.

Termin: Donnerstag, den 10. November 2016, 9:00 Uhr 17:30 Uhr, Kongresshaus Kap Europa in Frankfurt

Anmeldung und weitere Informationen unter: https:// www.scheer-group.com/unternehmen/aktuelles-events/ events/scheer-digital-world-congress/

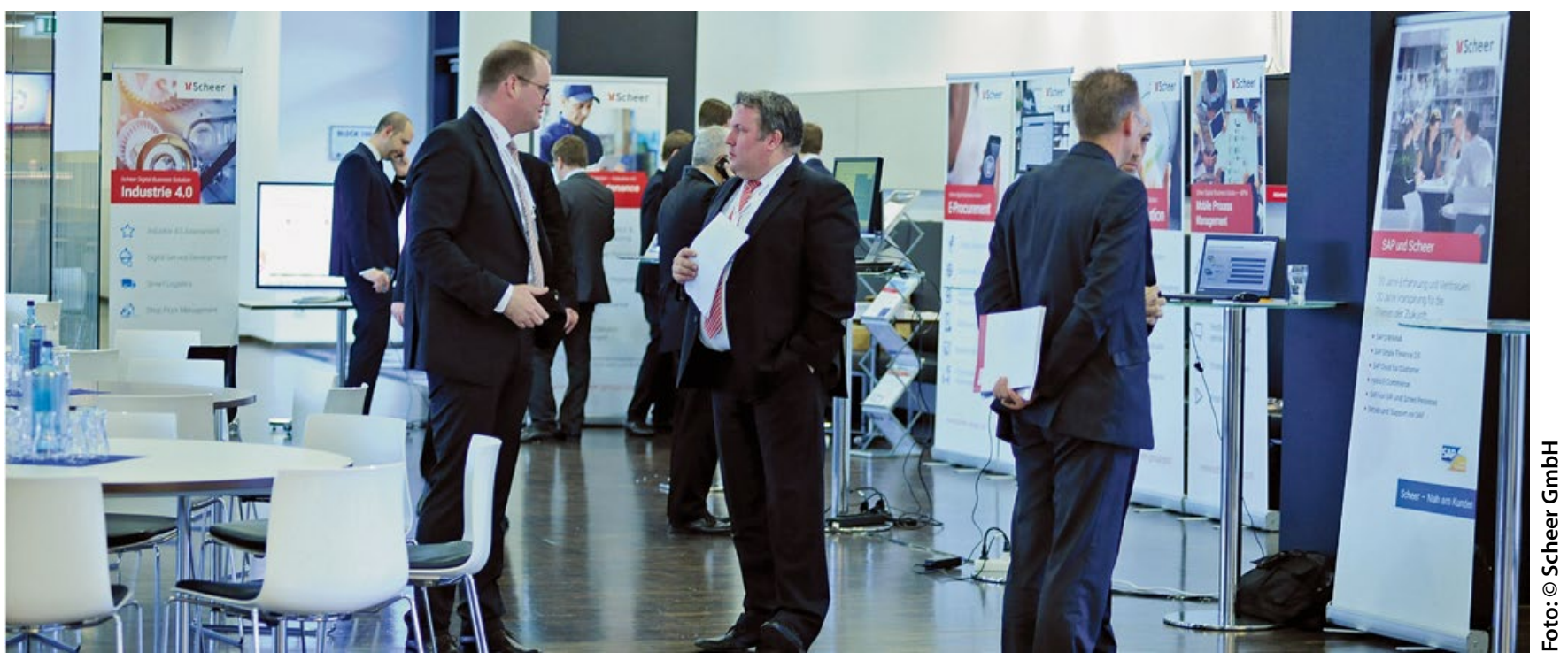

Auf dem Digital World Congress 2015 